\title{
Morphometric Study of Cricoid Cartilages in Adults by Dissection Method
}

\author{
Dr. Savitha $\mathrm{V}^{1^{*}}$, Dr. Sharada B. Menasinkai ${ }^{2}$
}

${ }^{1}$ Assistant Professor, Department of Anatomy, Adichunchanagiri Institute of Medical Sciences affiliated to Adichunchanagiri University, B.G Nagara. 571448 Karnataka, India

${ }^{2}$ Professor \& Head, Department of Anatomy, Adichunchanagiri Institute of Medical Sciences Affiliated to Adichunchanagiri University, B.G Nagara. Karnataka, India

DOI: $\underline{10.36348 / \text { sijap.2020.v03i03.001 }}$

| Received: 06.03.2020 | Accepted: 13.03.2020 | Published: 21.03 .2020

*Corresponding author: Dr. Savitha V

Abstract

Background: Out of different cartilages of larynx, cricoid is the strongest cartilage. It is the only cartilage which extends completely around the air passage. Renewed interest in subglottic stenosis recently has underscored the importance of detailed knowledge of cricoid cartilage. Aim: To study morphometric features of cricoid cartilage in adult human cadavers and also to compare the measurements of the cricoid cartilage between male and female. Materials \& Methods: Larynx specimens of South Indian population, were collected from 62 cadavers (Male: 31, Female: 31 ) from postmortem bodies from the department of Forensic medicine, MMC and RI, Mysore for a period of 18 months from Nov 2013 to April 2015. Following four parameters like height of arch and lamina, outer Antero-Posterior and Transverse diameters were measured using digital vernier caliper in $\mathrm{mm}$ on each cricoid cartilage and the observations were tabulated. Results: Mean value of height arch of cricoid cartilage was $5.97 \pm 0.94$ in male and 4.94 \pm 1.01 in female. Mean value of height of lamina was $21.3 \pm 1.9$ in male, $17.91 \pm 2.29$ in female. Mean value of outer antero-posterior (AP) diameter was $23.84 \pm 2.43$ in males and 19.18 \pm 2.34 in female. The mean value of outer transverse diameter was $25.53 \pm 2.23$ in male and19.29 \pm 2.52 in female. Conclusion: The mean values of all parameters of cricoid cartilage were more in males compared to females. The mean value of outer AP diameter was equal to the mean transverse diameters in females. Where as in males and the mean transverse diameter was more than AP diameter.

Keywords: larynx, cricoid cartilage, morphometry, sex differentiation.

Copyright @ 2020: This is an open-access article distributed under the terms of the Creative Commons Attribution license which permits unrestricted use, distribution, and reproduction in any medium for non-commercial use (NonCommercial, or CC-BY-NC) provided the original author and source are credited.

\section{INTRODUCTION}

From embryologic, anatomic, physiologic and surgical standpoints, the larynx is one of the most complex organs of human body [1]. Morphometric data of the larynx is useful in otorhinolaryngology during procedures like intubation, endoscopy, laryngeal microsurgeries, phonosurgery, stenting, cricothyroidotomy and transplantation [2].

A basic knowledge of anatomy of larynx is necessary for those who are involved in fields of surgical treatment of larynx such as speech therapists, anesthetists, oncologists, pulmonologists, radiologists, general practitioners, ENT surgeons and phoneticians [3].

Skeletal framework of larynx is formed by series of cartilages like unpaired thyroid, cricoid and epiglottis and paired arytenoids, cuneiform and corniculate [4]. Further, the growing utilization of advanced electrophysiological and surgical methods in management of some of the laryngeal disorders like subglottic stenosis and post intubation stenosis of lower respiratory tract, require an intense comprehension of size and proportion of human larynx and its cartilaginous components, especially the cricoid cartilage $[5,6]$.

A signet shaped ring, cricoid is the only complete cartilaginous ring of larynx. The cartilage consists of a posterior quadrate lamina and a narrow anterior arch. The cricoid is composed of hyaline cartilage, which undergoes variable ossification with advancing age which is especially pronounced in lamina $[7,8]$. The diameters of the cricoid cartilage vary a lot and studies have found that it is oval in shape, with males having a larger cricoid cartilage compared to females [9].

Many studies have been done on thyroid cartilage but only a very few have been done on the cricoid cartilage. So this study was intended to provide 
information about this significant but relatively neglected laryngeal cartilage. Therefore, the aim of this study was to assimilate precise and reliable morphometric data of human cadaveric cricoid cartilages.

\section{MATERIALS AND METHODS}

The 62 (31 Male, 31 Female) postmortem larynx specimens of South Indian population were collected from the department of Forensic medicine, MMC and RI, Mysore. Study was done for a period of 1 1/2 years from Nov 2013 to April 2015. A written consent was taken from the relatives of the subject. The study includes post-mortem larynx specimens of both the sexes of adult age group (18 to 70 years). Postmortem larynx specimens of hanging, strangulation, lacerated wound over the neck, with history of any previous laryngeal surgery and larynx specimens of below 18 years, above 70 years age group were excluded.

Soon after postmortem, larynx specimens extending from Hyoid bone to trachea were collected prospectively and fixed in $10 \%$ formalin solution. Careful dissection was done after fixation, to isolate Cricoid cartilages by removing muscles, ligaments, small cartilages and mucous membrane. Height of arch and lamina were measured as shown in figure 01, AP and transverse diameters were measured from inferior aspect of cricoids cartilage as shown in figure 02 . Measurements were taken with the help of digital vernier caliper and tabulated.

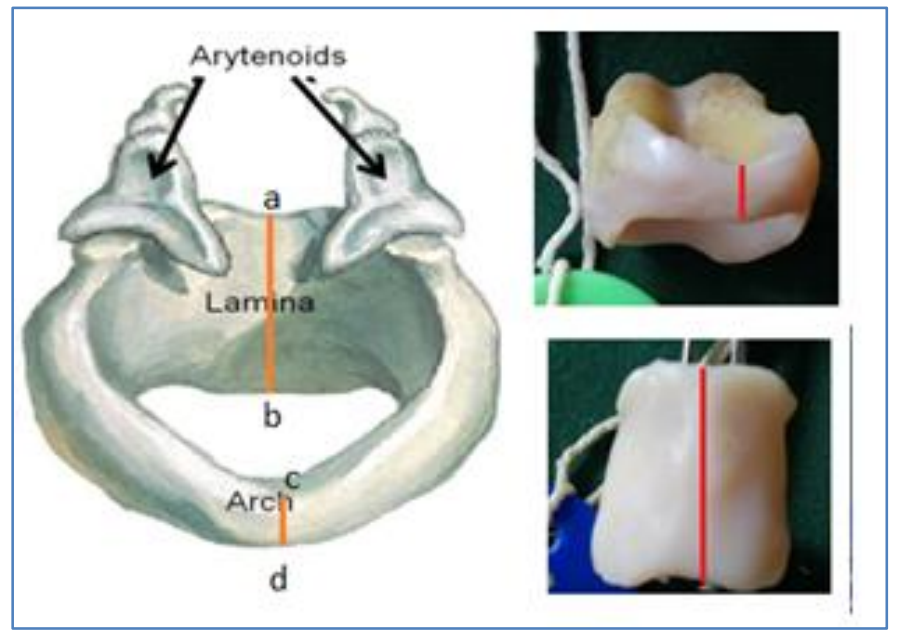

Fig-1: Superior aspect of cricoid cartilage: ab - height of lamina, cd - height of arch

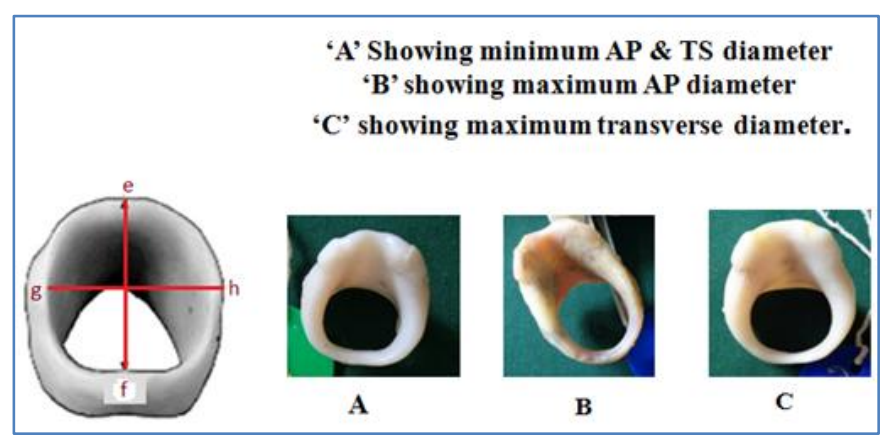

Fig-2: Inferior aspect of cricoid cartilage: ef -antero-posterior diameter, gh - transverse diameter

\section{OBSERVATIONS}

The mean values of all parameters of cricoid cartilage were more in males compared to females. The mean value of outer AP diameter was equal to the mean transverse diameters in females. Where as in males and the mean transverse diameter was more than AP diameter (Table 01).

Table-1: Comparision of Parameters of Cricoid cartilage between male and female

\begin{tabular}{|l|l|l|}
\hline Parameters & Male (31) & Female (31) \\
\hline Height of Arch & $5.97 \pm 0.94$ & $4.94 \pm 1.01$ \\
\hline Height of Lamina & $21.3 \pm 1.90$ & $17.91 \pm 2.29$ \\
\hline Antero-posterior diameter & $23.84 \pm 2.43$ & $19.18 \pm 2.34$ \\
\hline Transverse diameter & $25.53 \pm 2.23$ & $19.29 \pm 2.52$ \\
\hline
\end{tabular}




\section{DISCUSSION}

Cricoid cartilage has important clinical implications in placements of stents, transplantation, endotracheal tubes and for surgical procedures. Shibin Mathews reports in his article under physiologic variants of cricoid cartilage as "In a Swedish study by Randestad et al., laryngeal dimensions were taken from 34 men and 27 women, demonstrating the dimensional differences of the inner cricoid ring. In women, the mean diameter was $11.6 \mathrm{~mm}$ (range: 8.9 to $17.0 \mathrm{~mm}$ ), and in men, the mean diameter was $15.0 \mathrm{~mm}$ (range: 11.0 to $21.5 \mathrm{~mm}$ ) [10].

The mean values of height of the cricoid arch and lamina in males and females in the present study are less than the mean values of all other studies $[1,5$, $9,11]$ as shown in table 02 .

Table-2: Comparison of Parameters of present study with other studies

\begin{tabular}{|l|l|l|l|l|l|}
\hline Authors & Sample size & Ht of arch & Ht of lamina & $\begin{array}{l}\text { AP outer } \\
\text { diameter }\end{array}$ & $\begin{array}{l}\text { Transverse } \\
\text { outer dia. }\end{array}$ \\
\hline \multirow{2}{*}{ Monica Jain et al. [5] } & $\mathrm{M}(20)$ & $6.0 \pm 0.8$ & $22.0 \pm 1.9$ & $28.6 \pm 4.9$ & $25.7 \pm 3.2$ \\
\cline { 2 - 6 } & $\mathrm{Fe}(20)$ & $5.6 \pm 1.0$ & $19.9 \pm 2.3$ & $23.2 \pm 4.1$ & $21.3 \pm 4.7$ \\
\hline Mohini Joshi et al. [1] & 50 & $6.54 \pm 1.23$ & $21.45 \pm 1.97$ & $19.29 \pm 2.47$ & $18.33 \pm 2.26$ \\
\hline \multirow{2}{*}{ Rajan Kumar SIngla et al. [9] } & $\mathrm{M} \mathrm{(25)}$ & $7.56 \pm 1.15$ & $21.81 \pm 2.98$ & $20.01 \pm 3.8$ & $24.77 \pm 3.43$ \\
\cline { 2 - 6 } & $\mathrm{Fe} \mathrm{(5)}$ & $7 \pm 0.53$ & $18.55 \pm 0.65$ & $19.89 \pm 1.41$ & $21.94 \pm 0.52$ \\
\hline \multirow{2}{*}{ Ik Sung Kim et al. [11] } & $\mathrm{M} \mathrm{(33)}$ & $7.10 \pm 0.23$ & $22.33 \pm 0.44$ & $18.78 \pm 0.47$ & $17.19 \pm 0.40$ \\
\cline { 2 - 6 } & $\mathrm{Fe}(15)$ & $5.72 \pm 0.29$ & $20.10 \pm 0.59$ & $15.97 \pm 0.54$ & $13.36 \pm 0.50$ \\
\hline Present study (2019) & $\mathrm{M} \mathrm{(31)}$ & $5.97 \pm 0.94$ & $21.3 \pm 1.9$ & $23.84 \pm 2.43$ & $25.53 \pm 2.23$ \\
\cline { 2 - 6 } & $\mathrm{Fe} \mathrm{(31)}$ & $4.94 \pm 1$ & $17.91 \pm 2.29$ & $19.18 \pm 2.34$ & $19.29 \pm 2.52$ \\
\hline
\end{tabular}

In the present study the mean values of Antero-posterior diameter and transverse diameters in both sexes are less than the mean values quoted by other authors $[1,9,11]$.

In the present study the mean value of transverse diameter is equal to mean value of AP diameter in females where as in males the mean value of transverse diameter is more than antero posterior diameter.

A study done by Singla R K [9] reports that transverse diameter of cricoid cartilage is more than Antero-posterior diameter of cricoid cartilage in both sexes. Whereas majority of authors have shown the converse that is antero-posterior diameter being greater than the transverse diameter.

Comparison of these outcomes to other works reveals that the morphology of the cricoid cartilage varies amongst populations in most of the parameters. This may well be due to diversity in body shape and race. The big variation in almost all sizes and shapes of the cricoid cartilage renders it hard to standardize the rigid stents utilized in these organs. Consequently appropriate sized endo-tracheal tubes should be used for intubation, taking into consideration the sex and race of the individual, apart from other factors. Understanding of such measurements and differences is of paramount importance for clinical practice in order to prevent needless damage to the larynx [3].

\section{CONCLUSION}

Mean values of all parameters of cricoid cartilage were found to be more in male than female.
Significant difference was noted in values of cricoid arch and lamina in male and female laryngeal specimens $(\mathrm{p}<0.05)$. AP \& transverse diameters in male were more than female laryngeal specimens. Transverse diameter was more than AP in males and equal in females. Morphometrical data of the cricoid cartilage may be very useful in endotracheal intubation, laryngeal microsurgery and laryngeal framework surgery. These parameters can be helpful in evaluation of subglottic stenosis and its surgical repair.

\section{REFERENCES}

1. Mohini, J., Sharada, J., \& Subhash, J. (2011). Morphometric study of cricoid cartilages in Western India. AMJ: 4, 10: 542-547.

2. Mohini, M. J., Sharada, S.J., Subhash, D.J.(2011). The morphological study of adult human larynx in a western Indian population. Journal of laryngology and voice; 1(2): 50-54.

3. Viswanathan, A., Harikesh, S., Ashwini, S., Satyanjaya, S.(2018). Morphometric analysis of human cricoid cartilage: a cadaveric study. International Journal of Otorhinolaryngology and Head and Neck Surgery, 4(1):63-67.

4. Standring, S. (2008). The larynx. In: Gray's Anatomy, The anatomical basis of clinical practice. $40^{\text {th }}$ edn. Philadelphia: London. Churchill Livingstone, 577-80.

5. Monica, J., Usha, D. (2008). Morphometry of the Thyroid and Cricoid Cartilages in Adults. $J$ of Anatomical Society of India, 57(2):119-123.

6. Ajmani, M.L.(1990). A metrical study of laryngeal skeleton in adult Nigerians. J Anat. 171:187-91. 
7. Ajmani, M.L., Jain, S.P., Saxena, S.K.(1980). A metrical study of laryngeal cartilages and their ossification. Anat Anz, 148(1):42-8.

8. Romanes, G.J.(1986). The larynx, In: Cunningham'sManual of Practical Anatomy vol.3 Head, Neck and Brain.15th ed. Edinburgh: Oxford University Press; 157- 66.

9. Singla, R. K., Kaur, R., \& Laxmi, V. (2015). Morphology and morphometry of adult human cricoid cartilage: A cadaveric study in North Indian population. Int J Anat Res, 3(1), 910-14.

10. Mathews, S., \& Jain, S. (2019). Anatomy, Head and Neck, Cricoid Cartilage. In StatPearls [Internet]. StatPearls Publishing.

11. Kim, I. S., \& Song, C. H. (2017). Morphometric Study of Cricoid Cartilage in Korean. Korean Journal of Physical Anthropology, 30(1), 15-20. 